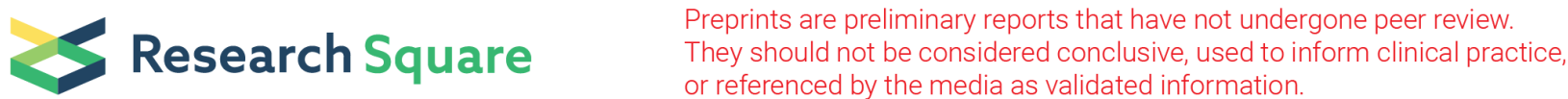 \\ Baropodometric parameters variation with body weight loss: a prospective cohort study
}

\section{Carla Lanuza-Cerzócimo}

Fundacio Universitaria del Bages

Javier Alfaro-Santafé

Fundacio Universitaria del Bages

Alejandro-Jesús Almenar-Arasanz

Fundacio Universitaria del Bages

José-Víctor Alfaro-Santafé

Fundacio Universitaria del Bages

Aitor Pérez-Morcillo

Fundacio Universitaria del Bages

Antonio Gómez-Bernal ( $\nabla$ agomez@umanresa.cat )

Fundacio Universitaria del Bages https://orcid.org/0000-0003-4005-9835

\section{Research article}

Keywords: Static, Dynamic, Postural Imbalance, Pressure, Obesity

Posted Date: April 9th, 2020

DOI: https://doi.org/10.21203/rs.3.rs-20653/v1

License: @ (i) This work is licensed under a Creative Commons Attribution 4.0 International License. Read Full License 


\section{Abstract}

Background One of the major public health problems of the 21 st century is obesity. Baropodometry is commonly used to determine specific loads on the plantar surface of the foot and the comportment of the body center of pressure (CoP). To evaluate the redistribution of the baropodometric parameters: static and dynamic plantar pressures and antero posterior CoP, by decreasing body weight.

Methods A sample of 43 subjects (24 male, 19 female) participated in the study. A hypocaloric diet was designed with the aim to reduce their body weight. The baropodometric exam was performed in two occasions: weight 1 - Session 1 and weight 2 - Session 2, when they had lost between 12 and $18 \mathrm{~kg}$. The foot was divided in 9 areas: heel, midfoot, 5 metatarsal heads (MTHs), Hallux, 2-5 toes. The Footwork® pressure platform was used to carry out the evaluation.

Results Subjects reduce an $11.59 \%$ their mean weight. Foot pressure decrease was statistically significant between the first and second measurements ( $\mathrm{p}<0.05)$. For the static on the Hallux, 2 nd MTH, 3 rd MTH, 5 th MTH and heel, while for the dynamic the pressure decreases on the whole study areas except on the 2 nd and 5 th toes. For the CoP, a notable posterior displacement was observed. There were no gender differences.

Conclusion We can conclude that weight loss affected positively to both plantar pressures and CoP, since statistically significant changes were observed in the baropodometric parameters between the two times studied.

\section{Introduction:}

Obesity is in one of the major public health problems of the 21 st century and its prevalence has tripled in many European countries in the last decades (1). It is a strongly problem associated with a lower quality of life, as well as with the development of serious chronic metabolic, cardiac and circulatory pathologies and musculoskeletal disorders $(2,3)$. Quantitative data showed that excessive body weight negatively effects on standing and walking $(4,5)$.

Plantar pressure measurement is commonly used to determine specific loads on the plantar surface of the foot. There are many case studies that assess pressures of the normal foot and try to establish patterns of pathological pressures (6). The CoP represents the average of all the weight that is in contact with the surface of the floor and is expressed as the point where the vector of the vertical reaction forces of the soil is located $(6,7)$.

In the literature it can be found how body weight influences on plantar pressure data and on the position of the CoP (810). Excesses of body weight has shown to have negative structural consequences in the feet and lower limbs (11-14). Obesity is also related with an anterior displacement of the CoP (15), since the instability in obese people, associated to weight increasing, seems to be determinant with CoP in an anterior position (16).

Computerized baropodometry is helpful for foot diseases diagnosis, foot function evaluation and to follow-up the treatment. It has been practiced to determine specific weight parameters in obese adults, among others $(10,14)$. Nonetheless, there are not in the literature specific studies that have analyzed by computerized baropodometry how plantar pressures and CoP improve by decreasing body weight in obese adults.

Therefore, with this study we aim to evaluate plantar pressures and antero - posterior CoP improvement by decreasing body weight in static and dynamic baropodometry data collection in obese adults.

\section{Methods:}

\section{Design and sample}


Between June 2017 and October 2017, we performed a prospective cohort study. The design of the present research was based on and executed according to the STROBE reporting guideline. The study was approved by the Ethics Committee of Clinical Research of Aragón (CEICA) with number C.P.-C.I. PI17/0203. Participants voluntarily signed an informed consent. The study has been conducted in accordance with the Helsinki Principles.

Participants were recruited at one Endocrinology and Nutrition private clinic in Huesca, Spain. Inclusion criteria included overweight subjects between 18 and 65 years old, medical weight loss indicated, no lower limb or spine pathology that might affect normal gait, nor structural or functional deformities in the feet. Candidates who did not comply inclusion criteria, or reported pain in their feet within the previous 6 months, or had any previous foot surgery were excluded.

\section{Procedure}

Participants were rigorously evaluated by the same endocrine doctor and podiatrist at baseline (Session 1) and at the end of the study after weight loss intervention (Session 2), when each participant had lost between $11-12 \%$ of its corporal weight. Therefore, we obtained 2 weight related with the two sessions: Session 1 - Weight 1; Session 2 Weight 2.

In order to achieve the proposed weight loss, lifestyle modification was applied (17): A specific very low-calorie diet (< $800 \mathrm{kcal} /$ day), and 2 daily sessions of 15 minutes of anaerobic physical exercise depending on the capacity of the participants, were designed $(18,19)$.

At Session 1 and Session 2, before and after weight loss intervention, participants were subjected to a baropodometric examination (static and dynamic). It allowed to quantitatively mapping pressures in each segment of the plantar surface $(20,21)$. For the static, participants were asked to stand in the center of the platform for 5 seconds, with their arms on either side of the body in a natural position looking straight ahead (22). To minimize individual's corporal fluctuations in static (as body weight oscillation and imbalance) we applied this procedure 3 times per session (22). For the dynamic, participants were asked to walk barefoot on the platform at their normal pace following the 3-step protocol, which requires landing on the platform on the third step of gait (23). To minimize individual's corporal fluctuations in dynamic (as body weight oscillation, imbalance and changes in gait speed) we applied this procedure 3 times per session (22). Both feet were subdivided into 9 areas: heel, midfoot, 5 MTHs, the Hallux, 2-5 toes (Fig. 1). Selection of the areas of the present study is justified because it is based on the daily clinic, where the consultations of overweight patients are usually due to discomfort or pain in $\mathrm{MTH}$, reason why these are studied separately and is supported by authors like Hills et al. (11), who performed a complete study of the differences of pressures between obese and non-obese subjects.

\section{<Figure 1 goes here>}

Peak pressures of these areas in $\mathrm{kg} / \mathrm{cm} 2$ and the position of the CoP, were obtained using the Footwork $\AA$ software (20). Peak pressure data were graphically exposed and related with the two weights for each patient.

\section{Equipment}

Footwork® platform (AM3-IST®, France), was used for the baropodometric analysis (22, 24), (Fig. 2).

$<$ Figure 2 goes here>

Participant's weight and height were measured during each session with an Año-Sayol scale and stadiometer, respectively (Año-Sayol SL, Barcelona, Spain).

\section{Statistical Analysis}


An initial exploratory analysis of all clinical variables was carried out. Continuous variables were expressed as mean \pm standard deviation (SD), whereas qualitative variables were expressed as frequencies and percentages. Continuous data were checked for normality by Kolmogorov-Smirnov Test. Chi-Square Test was applied to show the relationship between qualitative variables. To compare mean weights between two independent groups according to normality, we used Student's-T Test and ANOVA Test to " $m$ " groups. Differences between Session 1 and Session 2, were performed using mean comparison methods, Wilcoxon when the variable did not follow normal distribution, and Student's $T$ for related samples when there was normality. To quantify the difference between weight and plantar pressures and the CoP at Session 1 and Session 2 the "change percentage" was calculated, which was defined as the relative variation in percentage points between both sessions: Weight-Change \% (WC\%) $=[($ Weight at Session $2-$ Weight at Session 1)/ Weight Session 1] x 100; Plantar-Pressure-Change \% (PPC\%) $=[($ Pressure at Session $2-$ Pressure at Session 1)/ Pressure at Session 1] x 100; CoP-Change \% = [(time CoP X + 1 - time CoP X)/ time CoP X] x 100. The "change percentage" was analyzed through Spearman correlation coefficient, according to normality.

The "improve" variable was established in order to analyze the possible relationship between weight loss and the 9 pressure foot areas considered at Session 1 and Session 2 for both: static and dynamic baropodometry. Statistical significance level was set at $p<0.05$, confidence level set in the comparisons was $95 \%$. The statistical analyses were performed using the SPSS software 22.0 for Windows (SPSS Ibérica, Madrid, Spain).

\section{Results:}

The mean comparison of the two weights studied is shown in Table 1. The loss of weights between both times was statistically significant $(p<0.05)$. As well there can be observed the weight differences between genders which had no statistical significance.

\section{Table 1}

Mean comparison and Statistical group.

\begin{tabular}{|c|c|c|c|c|c|c|c|c|}
\hline \multicolumn{6}{|c|}{ Mean comparison } & \multicolumn{3}{|l|}{ Statistical group } \\
\hline & \multirow[t]{2}{*}{ MEAN } & SD & \multicolumn{2}{|l|}{ CL $95 \%$} & $\begin{array}{l}{ }^{*} \mathrm{P} \\
\text { value }\end{array}$ & & $\begin{array}{l}\text { Male } \\
(\mathrm{N}=24)\end{array}$ & $\begin{array}{l}\text { Female } \\
(\mathrm{N}=19)\end{array}$ \\
\hline & & & \multicolumn{3}{|l|}{ LL UL } & $\begin{array}{l}\text { Weight } 1(\mathrm{~kg}) \text { - } \\
\text { Mean (SD) }\end{array}$ & $\begin{array}{l}87.304 \\
(16.7965)\end{array}$ & $\begin{array}{l}68.305 \\
(4.7354)\end{array}$ \\
\hline \multirow{3}{*}{$\begin{array}{l}\text { Weight } \\
1-2\end{array}$} & \multirow[t]{3}{*}{9.0837} & 1.9689 & 8.4778 & 9.6897 & 0.001 & & \multicolumn{2}{|c|}{${ }^{\star} \mathrm{p}$ valor $=0.000$} \\
\hline & & & & & & $\begin{array}{l}\text { Weight } 2(\mathrm{~kg})- \\
\text { Mean }(\mathrm{SD})\end{array}$ & $\begin{array}{l}77.229 \\
(15.7495)\end{array}$ & $\begin{array}{l}60.474 \\
(4.6207)\end{array}$ \\
\hline & & & & & & & \multicolumn{2}{|c|}{${ }^{*} \mathrm{p}$ valor $=0.000$} \\
\hline \multicolumn{9}{|c|}{ *T- Student Test for related samples } \\
\hline \multicolumn{9}{|c|}{ Abbreviations: SD = Standard deviation / CL = Confidence Level $/$ LL = Lower Limit $/$ UP = Upper Limit } \\
\hline
\end{tabular}

$<$ Table 1 goes here>

Table 2 shows the analysis of the relationship between the dependent variable (change CoP \%) and the independent variables (gender and change weight \%), which aims to find a predictive equation. Independent variables have a $23.1 \%$ explanatory capability about the comportment of the dependent variable. 
Table 2

Regression coefficients.

\begin{tabular}{|lllllll|}
\hline Model & \multicolumn{2}{l}{ Non standardized coefficient } & Standardized coefficient & t & Sig. \\
\hline & Beta & Typical error & Beta & & \\
\hline (Constant) & 45.902 & 16.065 & & 2.857 & .007 \\
\hline Gender & 0.190 & 4.994 & 0.005 & .038 & .970 \\
\hline Weight 1-2 & 3.380 & 1.350 & 0.353 & 2.505 & 0.017 \\
\hline *Dependent variable: CoP 1-2 & & & \\
\hline
\end{tabular}

$<$ Table 2 goes here>

Predictive equation:

Cop-Change $\%=45.902+0.190 *$ GENDER $+3.380 *$ CHANGE $\%$ WEIGHT $1-2$

Weight was a significant variable, when the change weight \% increases in one unit the change CoP increases $3.380 \%$. There were no statistically significant gender differences.

For the plantar pressures, in static, Table 3, a statistically significant mean pressure decrease between the first and the second measurement on the Hallux, 2nd MTH, 3rd MTH, 5th MTH and heel was observed. 
Table 3

Statistics for all the analyzed variables (9 pressure areas studied) for the static measurement.

\begin{tabular}{|c|c|c|c|c|c|c|c|}
\hline Variable & Mean & IC lower & IC higher & Median & Minimum & Maximum & $p$ \\
\hline $\mathrm{S}-\mathrm{Hx}(1)$ & 0.066 & 0.043 & 0.089 & 0.000 & 0.00 & 0.61 & $0.517 *$ \\
\hline $\mathrm{S}-\mathrm{Hx}(2)$ & 0.047 & 0.026 & 0.069 & 0.000 & 0.00 & 0.65 & $0.050 *$ \\
\hline S-1MTH (1) & 0.524 & 0.484 & 0.565 & 0.480 & 0.21 & 1.15 & $0.045^{*}$ \\
\hline S-1MTH (2) & 0.509 & 0.462 & 0.557 & 0.465 & 0.19 & 1.36 & $0.635^{*}$ \\
\hline S-2MTH (1) & 0.688 & 0.644 & 0.732 & 0.660 & 0.29 & 1.24 & $0.057 * *$ \\
\hline S-2MTH (2) & 0.611 & 0.552 & 0.669 & 0.570 & 0.26 & 2.23 & $0.001 * *$ \\
\hline S-3MTH (1) & 0.696 & 0.649 & 0.742 & 0.680 & 0.27 & 1.38 & $0.017 * *$ \\
\hline S-3MTH (2) & 0.637 & 0.577 & 0.697 & 0.590 & 0.27 & 2.28 & $0.017 * *$ \\
\hline S-4MTH (1) & 0.559 & 0.518 & 0.600 & 0.525 & 0.23 & 1.18 & $0.020 * *$ \\
\hline S-4MTH (2) & 0.536 & 0.486 & 0.586 & 0.495 & 0.19 & 1.49 & $0.342 * *$ \\
\hline S-5MTH (1) & 0.363 & 0.317 & 0.409 & 0.325 & 0.12 & 1.59 & $0.107 *$ \\
\hline S-5MTH (2) & 0.336 & 0.277 & 0.396 & 0.295 & 0.06 & 1.95 & $0.003^{*}$ \\
\hline S-2-5 (1) & 0.017 & 0.006 & 0.028 & 0.000 & 0.00 & 0.34 & $0.464^{*}$ \\
\hline$S-2-5(2)$ & 0.142 & 0.007 & 0.022 & 0.000 & 0.00 & 0.18 & $0.780 *$ \\
\hline S-HEEL (1) & 0.887 & 0.808 & 0.967 & 0.830 & 0.34 & 2.73 & $0.081 * *$ \\
\hline S-HEEL (2) & 0.784 & 0.723 & 0.845 & 0.770 & 0.15 & 1.95 & 0.001 ** \\
\hline S-MID (1) & 0.093 & 0.069 & 0.117 & 0.000 & 0.00 & 0.45 & $0.128 *$ \\
\hline S-MID (2) & 0.092 & 0.061 & 0.123 & 0.030 & 0.00 & 1.03 & $0.322 *$ \\
\hline \multicolumn{8}{|c|}{ * Wilcoxon Test } \\
\hline \multicolumn{8}{|c|}{ 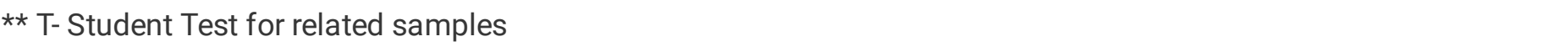 } \\
\hline \multicolumn{8}{|c|}{$\begin{array}{l}\text { Abbreviations: } \mathrm{S}=\text { static } / 1=\text { weight } 1 / 2=\text { weight } 2 / \mathrm{Hx}=\text { Hallux } / \mathrm{MTH}=\text { metatarsal head } / 2-5=2-5 \text { toes } / \mathrm{HEEL} \\
=\text { heel } / \mathrm{MID}=\text { midfoot. }\end{array}$} \\
\hline
\end{tabular}

$<$ Table 3 goes here $>$

In dynamic, Table 4, a statistically significant pressure decrease between the first and second measurements on the Hallux, 1st MTH, 2nd MTH, 3rd MTH, 4th MTH, 5th MTH, heel and midfoot was observed. In summary all study areas except in the 2 nd to 5 th toes. 
Table 4

Statistics for all the analyzed variables (9 pressure areas studied) for the dynamic measurement

\begin{tabular}{|c|c|c|c|c|c|c|c|}
\hline Variable & Mean & IC lower & IC higher & Median & Minimum & Maximum & $p$ \\
\hline $\mathrm{D}-\mathrm{Hx}(1)$ & 0.832 & 0.654 & 1.009 & 0.500 & 0.00 & 4.04 & $0.364^{*}$ \\
\hline $\mathrm{D}-\mathrm{Hx}(2)$ & 0.660 & 0.527 & 0.793 & 0.515 & 0.03 & 3.39 & $0.043^{*}$ \\
\hline D-1MTH (1) & 1.419 & 1.292 & 1.547 & 1.300 & 0.52 & 3.39 & $0.001 *$ \\
\hline D-1MTH (2) & 1.130 & 1.023 & 1.238 & 1.085 & 0.45 & 2.78 & $0.000 *$ \\
\hline D-2MTH (1) & 2.202 & 2.047 & 2.356 & 2.060 & 0.95 & 4.01 & 0.001 ** \\
\hline D-2MTH (2) & 1.830 & 1.666 & 1.995 & 1.710 & 0.67 & 4.15 & $0.000 * *$ \\
\hline D-3MTH (1) & 2.269 & 2.100 & 2.437 & 2.115 & 0.94 & 4.06 & $0.003^{* \star}$ \\
\hline D-3MTH (2) & 1.870 & 1.687 & 2.053 & 1.580 & 0.63 & 4.74 & $0.000 * *$ \\
\hline D-4MTH (1) & 1.585 & 1.445 & 1.726 & 1.415 & 0.61 & 3.90 & $0.004^{*}$ \\
\hline D-4MTH (2) & 1.313 & 1.168 & 1.457 & 1.140 & 0.42 & 3.56 & 0.000 * \\
\hline D-5MTH (1) & 0.889 & 0.737 & 1.040 & 0.735 & 0.18 & 4.67 & $0.052^{*}$ \\
\hline D-5MTH (2) & 0.723 & 0.610 & 0.837 & 0.600 & 0.14 & 3.35 & $0.011 *$ \\
\hline D-2-5 (1) & 0.142 & 0.115 & 0.168 & 0.130 & 0.00 & 0.56 & $0.477^{*}$ \\
\hline D-2-5 (2) & 0.127 & 0.103 & 0.150 & 0.105 & 0.00 & 0.58 & $0.315^{*}$ \\
\hline D-HEEL (1) & 1.506 & 1.326 & 1.687 & 1.350 & 0.52 & 5.57 & $0.001 *$ \\
\hline D-HEEL (2) & 1.156 & 1.032 & 1.280 & 1.025 & 0.35 & 3.39 & $0.000 *$ \\
\hline D-MID (1) & 0.180 & 0.118 & 0.241 & 0.140 & 0.00 & 2.28 & $0.314^{*}$ \\
\hline D-MID (2) & 0.149 & 0.061 & 0.237 & 0.000 & 0.00 & 3.59 & $0.003^{*}$ \\
\hline \multicolumn{8}{|c|}{ * Wilcoxon Test } \\
\hline \multicolumn{8}{|c|}{ 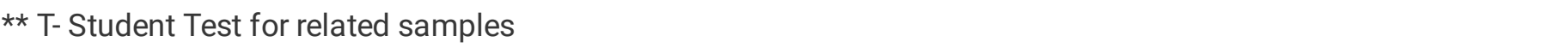 } \\
\hline \multicolumn{8}{|c|}{$\begin{array}{l}\text { Abbreviations: } \mathrm{D}=\text { dynamic } / 1=\text { weight } 1 / 2=\text { weight } 2 / \mathrm{Hx}=\text { Hallux } / \mathrm{MTH}=\text { metatarsal head } / 2-5=2-5 \text { toes } / \\
\mathrm{HEEL}=\text { heel } / \mathrm{MID}=\text { midfoot }\end{array}$} \\
\hline
\end{tabular}

$<$ Table 4 goes here $>$

Table 5 shows the descriptive analysis, as well as the number of patients $(n)$ considered in each case. The relationship between weight change and pressure change was studied using the Spearman correlation coefficient. 
Table 5

Change \% (1-2) static \& dynamic.

\begin{tabular}{|c|c|c|c|c|c|c|c|c|c|c|}
\hline Variable & Mean & $\begin{array}{l}\text { IC } \\
\text { lower }\end{array}$ & $\begin{array}{l}\text { IC } \\
\text { higher }\end{array}$ & Median & Minimum & Maximum & $\mathrm{n}$ & Coef. & $\mathrm{p}^{*}$ & \\
\hline \multirow[t]{9}{*}{ Static } & $\begin{array}{l}\mathrm{S}-\mathrm{Hx} \\
(1-2)\end{array}$ & 22.328 & -45.578 & 90.233 & -55.476 & -100.00 & 1050.00 & 42 & 0.328 & 0.034 \\
\hline & $\begin{array}{l}\text { S- } \\
1 \mathrm{MTH} \\
(1-2)\end{array}$ & -17.230 & -22.403 & -12.057 & -20.170 & -63.38 & 46.43 & 86 & 0.367 & 0.001 \\
\hline & $\begin{array}{l}\text { S- } \\
2 \mathrm{MTH} \\
(1-2)\end{array}$ & -10.293 & -16.493 & -4.093 & -10.790 & -53.23 & 171.95 & 86 & 0.309 & 0.004 \\
\hline & $\begin{array}{l}\text { S- } \\
\text { 3MTH } \\
(1-2)\end{array}$ & -7.036 & -13.647 & -0.424 & -9.245 & -51.72 & 204.00 & 86 & 0.327 & 0.002 \\
\hline & $\begin{array}{l}\text { S- } \\
4 \mathrm{MTH} \\
(1-2)\end{array}$ & 0.205 & -9.400 & 9.811 & -7.709 & -72.45 & 245.16 & 86 & 0.281 & 0.009 \\
\hline & $\begin{array}{l}\text { S- } \\
5 \mathrm{MTH} \\
(1-2)\end{array}$ & 0.749 & -13.969 & 15.467 & -10.644 & -74.21 & 457.14 & 86 & 0.034 & 0.757 \\
\hline & $\begin{array}{l}S-2-5 \\
(1-2)\end{array}$ & -4.958 & -93.826 & 83.909 & -96.296 & -100.00 & 450.00 & 18 & 0.458 & 0.056 \\
\hline & $\begin{array}{l}\text { S- } \\
\text { HEEL } \\
(1-2)\end{array}$ & -7.146 & -13.356 & -0.935 & -11.585 & -60.53 & 102.70 & 86 & -0.073 & 0.504 \\
\hline & $\begin{array}{l}\text { S-MID } \\
(1-2)\end{array}$ & -13.226 & -35.637 & 9.186 & -21.111 & -100.00 & 312.00 & 42 & -0.028 & 0.862 \\
\hline \multirow[t]{6}{*}{ Dynamic } & $\begin{array}{l}\mathrm{D}-\mathrm{Hx} \\
(1-2)\end{array}$ & 35.180 & -0.186 & 70.546 & -9.434 & -94.71 & 823.08 & 85 & -0.050 & 0.647 \\
\hline & $\begin{array}{l}\text { D- } \\
1 \mathrm{MTH} \\
(1-2)\end{array}$ & -14.623 & -22.387 & -6.860 & -21.156 & -74.38 & 114.96 & 86 & 0.022 & 0.838 \\
\hline & $\begin{array}{l}\text { D-2 } \\
\text { MTH } \\
(1-2)\end{array}$ & -14.718 & -20.971 & -8.465 & -15.614 & -65.09 & 141.28 & 86 & 0.059 & 0.590 \\
\hline & $\begin{array}{l}\text { D- } \\
\text { 3MTH } \\
(1-2)\end{array}$ & -15.236 & -21.818 & -8.654 & -17.618 & -67.24 & 134.97 & 86 & 0.117 & 0.283 \\
\hline & $\begin{array}{l}\text { D- } \\
4 \mathrm{MTH} \\
(1-2)\end{array}$ & -13.331 & -21.080 & -5.583 & -19.740 & -67.14 & 129.68 & 86 & 0.067 & 0.538 \\
\hline & $\begin{array}{l}\text { D- } \\
5 \mathrm{MTH} \\
(1-2)\end{array}$ & -1.667 & -15.119 & 11.786 & -19.917 & -89.12 & 242.11 & 86 & 0.055 & 0.617 \\
\hline
\end{tabular}

*Spearman correlation coefficient

Abbreviations: $\mathrm{S}=$ static $/ \mathrm{D}=$ Dynamic $/ 1-2=$ weight $1-2 / \mathrm{Hx}=$ Hallux $/ \mathrm{MTH}=$ metatarsal head $/ 2-5=2-5$ toes $/$ $\mathrm{HEEL}=$ heel $/ \mathrm{MID}=$ midfoot 


\begin{tabular}{|clllllllllll}
\hline Variable & Mean & $\begin{array}{l}\text { IC } \\
\text { lower }\end{array}$ & $\begin{array}{l}\text { IC } \\
\text { higher }\end{array}$ & Median & Minimum & Maximum & $\mathbf{n}$ & Coef. & p* \\
\hline $\begin{array}{c}\text { D-2-5 } \\
(1-2)\end{array}$ & 14.192 & -15.730 & 44.113 & -12.500 & -100.00 & 650.00 & 72 & 0.235 & 0.047 \\
\hline $\begin{array}{c}\text { D- } \\
\text { HEEL } \\
(1-2)\end{array}$ & -14.515 & -23.350 & -5.680 & -25.119 & -77.02 & 128.17 & 86 & 0.051 & 0.640 \\
\hline $\begin{array}{c}\text { D-MID } \\
(1-2)\end{array}$ & -39.858 & -54.502 & -25.213 & -36.232 & -100.00 & 112.50 & 52 & 0.297 & 0.032 \\
\hline
\end{tabular}

*Spearman correlation coefficient

Abbreviations: $\mathrm{S}=$ static $/ \mathrm{D}=$ Dynamic $/ 1-2=$ weight $1-2 / \mathrm{Hx}=$ Hallux $/ \mathrm{MTH}=$ metatarsal head $/ 2-5=2-5$ toes $/$ $\mathrm{HEEL}=$ heel $/ \mathrm{MID}=$ midfoot

$<$ Table 5 goes here>

In static, it is observed that the weight variation is statistically significant in the Hallux, 1st MTH, 2nd MTH, 3rd MTH and 4th MTH.

In dynamics between Session 1 and Session 2 we found only a significant association between pressure changes and weight variation in the 2 nd to 5 th toes and midfoot.

\section{Discussion:}

Changes in long - term posture, such as those produced by weight gain, may induce permanent degenerative changes in the musculoskeletal system (25). Therefore weight loss, will influence positively body posture, which can be perfectly verified by studying plantar pressure and the movement of the CoP (26).

In the present research there have been no significant changes between the variation of the CoP and the gender, as evidenced by Rogind et al. (27) and Nordahl et al. (28). But we have observed that the CoP moves backwards when losing weight. These results match with those obtained by DeVita et al. (29), who demonstrated that the CoP displaces forwards when weight increases. Gilleard and Smith in 2007 (16), emphasized this and added the hypothesis of the lack of stability in obese as a determinant of anterior displacement.

Obesity has been associated with greater forward movement of the center of pressures (15). Body mass gain in obese people generates an instability increasing which leads to a major muscular response to maintain the CoP in the center of the support polygon. The location of the fat mass in the body (thorax-abdominal in men; hips in women) contributes to the antero-posterior instability (30).

In the literature we find opposite opinions about the influence of the weight in plantar pressure values. Several studies agree that there is a direct correlation between both factors (11-13), i.e. weight influences plantar pressures, which has structural consequences in the feet and lower limbs (11).

Our findings showed that when weight decreased statistically significant differences were found on the MTHs in static and on the midfoot in dynamics (31). These findings are supported by Birtane et al. (32), who demonstrated that weight gain does not increase peak pressures of the forefoot walking, although it was found that the most sensitive anatomical area was 1st MTH where it was observed that weight gain increases peak pressures (13). 
In the study of Arnold et al. (33), they observed the correlation between higher plantar pressures when weight increases. There were studied three times: when subjects increase 5,10 and $15 \mathrm{~kg}$, being found the relation for the two latest weights on the Hallux, every MTHs and heel.

Riddiford-Harland et al. (34), justifies the fact that the middle zone is the most sensitive to pressure change due to the increase in the impact forces that limit the capacity of the medial longitudinal arch to attenuate this change and therefore the adaptation occurs by increase the support of the middle part of the foot (34). Arnold et al. (33) manifests that in his study this area does not appear as statistically significant because weight gains only reached up to $15 \mathrm{~kg}$, our study does not support this hypothesis since the weight loss oscillated between 5.5 and $13.2 \mathrm{~kg}$ and this was the only statistically significant area along with the toes.

In the case of Hills et al. it was noted that the most notable increase in peak pressure among non-obese and obese occurred on the middle region of the foot. Their study coincides with our data but with large differences in the mean of body mass between obese and non-obese subjects, $36.0 \mathrm{~kg}$ for women and $43.6 \mathrm{~kg}$ for men (11). Arnold bases his foundation on this study, that a greater variance in weight between both groups (obesity and non-obesity) more significant the difference on the middle zone (33).

The results of the present study can be related with those of Song et al. (35) and Mueller et al. (13), who defend that when the weight increases the plantar arch descends (more in pronated foot) increasing the load on the medial surface of the foot's sole, coinciding with our study.

One limitation of the present research should be highlighted, the lateral movement of the CoP as no considered. Anyway, the findings of this work reveal the important relationship between weight and musculoskeletal system.

We can conclude that weight loss positively affects the static CoP and plantar pressures, both static and dynamic, since there is observed statistically significant changes on antero - posterior CoP and plantar pressures between the two times studied. CoP moves backwards which means balance and healthy postural gain, it should be noted that weight reduction affects differently static and dynamic plantar pressures. We can observe that there is no anatomical area of the 9 studied which coincides between static and dynamic studies as statistically significant.

\section{Abbreviations}

- Cop

Center of Pressures

- MTH

Metatarsal Head

\section{Declarations}

Ethics approval and consent to participate

The study was approved by the Ethics Committee of Clinical Research of Aragón (C.P.-C.I.PI17/0203)

Consent for publication

Not applicable

Page 10/15 
Availability of data and materials

The datasets used and/or analysed during the current study are available from the corresponding author on reasonable request.

Competing interests

The authors declare that they have no competing interests.

Funding

Not applicable.

Authors' contributions

CL-C had the original idea of the present research, he designed the protocol, evaluated the children and designed the treatment. AG-B evaluated the children at baseline and after the follow-up. JA-S made the statistical analysis of the data. JVA-S performed the randomization, AP-M reviewed and wrote the manuscript, AJA-A reviewed and wrote the manuscript.

Acknowledgements (Declaration section)

Not applicable.

Authors' information (Declaration section)

All the co-authors of the present research are podiatrists and/or work in the field of podiatry assessing therapeutic protocols, making gait, biomechanical and posture analysis and studies. A very common musculoskeletal pain cause that we are used to manage with in the daily clinic, is calcaneal apophysitis. Reviewing the literature, we realize that there is no agreement for a preferred treatment, and that the evidence about orthopaedic devices in unclear. Based on that, we perform a research where we wanted to provide a pragmatic randomized comparative effectiveness with the aim to compare heel pain perception in children with calcaneal apophysitis using custom-made polypropylene foot orthoses and "off-the-shelf" heel-lifts.

\section{References}

1. -Monasta L, Batty GD, Cattaneo A, Lutje V, Ronfani L, Van Lenthe FJ, Brug J. Early-life determinants of overweight and obesity: a review of systematic reviews. Obes Rev. 2010 Oct;11(10):695-708.

2. -Buckley J. Exercise self-efficacy intervention in overweight and obese women. J Health Psychol. 2016 Jun;21(6):1074-84.

3. -Benítez-Andrades JA, Arias N, García-Ordás MT, Martínez-Martínez M, García-Rodríguez I. Feasibility of SocialNetwork-Based eHealth Intervention on the Improvement of Healthy Habits among Children. Sensors (Basel). 2020 Mar 4;20(5). pii: E1404.

Page $11 / 15$ 
4. -de Souza SA, Faintuch J, Valezi AC, Sant' Anna AF, Gama-Rodrigues JJ, de Batista Fonseca IC, Souza RB, Senhorini RC. Gait cinematic analysis in morbidly obese patients. Obes Surg. 2005 Oct;15(9):1238-42.

5. -Vismara L, Romei M, Galli M, Montesano A, Baccalaro G, Crivellini M, Grugni G. Clinical implications of gait analysis in the rehabilitation of adult patients with "Prader-Willi" Syndrome: a cross-sectional comparative study ("PraderWilli" Syndrome vs matched obese patients and healthy subjects). J Neuroeng Rehabil. 2007 May;10:4:14.

6. -Lee W, Hong SH, Oh HW. Characterization of Elastic Polymer-Based Smart Insole and a Simple Foot Plantar Pressure Visualization Method Using 16 Electrodes. Sensors (Basel). 2018 Dec 22;19(1). pii: E44.

7. -Gomez Bernal A, Becerro-de-Bengoa-Vallejo R, Losa-Iglesias ME. Reliability of the OptoGait portable photoelectric cell system for the quantification of spatial-temporal parameters of gait in young adults. Gait Posture. 2016 Oct;50:196-200.

8. -Ferrin B, Diego C, Magdalena X, Correa HL. Determinación semiautomática de parámetros morfológicos de la huella plantar mediante el procesamiento digital de imágenes. Sistemas Telemática. 2013;11(27):9-26.

9. -Puig-Diví A, Prats-Puig A. Postural and dynamic analysis of the human body: The relevance of the functional modulator factors in the methodological design. Multidisciplinary Journal for Education Social Technological Sciences. 2015;2(2):95-120.

10. -Wafai L, Zayegh A, Woulfe J, Aziz SM, Begg R. Identification of Foot Pathologies Based on Plantar Pressure Asymmetry. Sensors (Basel). 2015 Aug 18;15(8):20392-408.

11. -Hills AP, Hennig EM, McDonald M, Bar-Or O. Plantar pressure differences between obese and non-obese adults: a biomechanical analysis. Int J Obes Relat Metab Disord. 2001 Nov;25(11):1674-9.

12. -Menz HB, Morris ME. Clinical determinants of plantar forces and pressures during walking in older people. Gait Posture. 2006 Oct;24(2):229-36.

13. -Mueller MJ, Hastings M, Commean PK, Smith KE, Pilgram TK, Robertson D, Johnson J. Forefoot structural predictors of plantar pressures during walking in people with diabetes and peripheral neuropathy. J Biomech. 2003 Jul;36(7):1009-17.

14. -Taborri J, Palermo E, Rossi S, Cappa P. Gait Partitioning Methods: A Systematic Review. Sensors (Basel). 2016 Jan 6;16(1). pii: E66.

15. -Berrigan F, Simoneau M, Tremblay A, Hue O, Teasdale N. Influence of obesity on accurate and rapid arm movement performed from a standing posture. Int J Obes(Lond). 2006 Dec;30(12):1750-7.

16. -Gilleard W, Smith T. Effect of obesity on posture and hip joint moments during a standing task, and trunk forward flexion motion. Int J Obes(Lond). 2007 Feb;31(2):267-71.

17. -Fujioka K. Benefits of moderate weight loss in patients with type 2 diabetes. Diabetes Obes Metab. 2010 Mar;12(3):186-94.

18. -Siram AT, Yanagisawa R, Skamagas M. Weight management in type 2 diabetes mellitus. Mt Sinai J Med. 2010 SepOct;77(5):533-48.

19. -Anderson JW, Kendall CW, Jenkins DJ. Importance of weight management in type 2 diabetes: review with metaanalysis of clinical studies. J Am Coll Nutr. 2003;22:331-9.

20. -Fabris SM, Valezi AC, de Souza SA, Faintuch J, Cecconello I, Junior MP. Computerized baropodometry in obese patients. Obes Surg. 2006 Dec;16(12):1574-8.

21. -Gravante G, Russo G, Pomara F, Ridola C. Comparison of ground reaction forces between obese and control young adults during quiet standing on a baropodometric platform. Clin Biomech (Bristol Avon). 2003 Oct;18(8):780-2.

22. -Becerro de Bengoa Vallejo R, Losa Iglesias ME, Zeni J, Thomas S. Reliability and repeatability of the portable EPSplatform digital pressure-plate system. J Am Podiatr Med Assoc. 2013 May-Jun;103(3):197-203. 
23. -Peter EJG, Urukalo A, Fleischli JG, Lavery LA. Reproducibility of Gait Analysis Variables: One-Step versus Three-Step Method of Data Acquisition. J Foot Ankle Surg. 2002;41(4):206-12.

24. -Giacomozzi C. Appropriateness of plantar pressure measurement devices: a comparative technical assessment. Gait Posture. 2010 May;32(1):141-4.

25. -Hue O, Simoneau M, Marcotte J, Berrigan F, Doré J, Marceau P, Marceau S, Tremblay A, Teasdale N. Body weight is a strong predictor of postural stability. Gait Posture. 2007 Jun;26(1):32-8.

26. -Ruhe A, Fejer R, Walker B. The test-retest reliability of centre of pressure measures in bipedal static task conditionsa systematic review of the literature. Gait Posture. 2010 0ct;32(4):436-45.

27. -Røgind H, Lykkegaard JJ, Bliddal H, Danneskiold-Samsøe B. Postural sway in normal subjects aged 20-70 years. Clin Physiol Funct Imaging. 2003 May;23(3):171-6.

28. -Nordahl SH, Aasen T, Dyrkorn BM, Eidsvik S, Molvaer OI. Static stabilometry and repeated testing in a normal population. Aviat Space Environ Med. 2000 Sep;71(9):889-93.

29. -DeVita P, Hortobágyi T. Obesity is not associated with increased knee joint torque and power during level walking. $J$ Biomech. 2003 Sep;36(9):1355-62.

30. -Clark KN. Balance and strength training for obese individuals. ACSM's Health Fitness Journal. 2004;8(1):14-20.

31. -Bolte K, Hennig E, Hills A, McDonald M. Pressure changes under the feet of obese adults after a weight reduction program. Arch Physiol Biochem. 2000;108(1-2):70-0.

32. -Birtane $\mathrm{M}$, Tuna $\mathrm{H}$. The evaluation of plantar pressure distribution in obese and non-obese adults. Clin Biomech. 2004 Dec;19(10):1055-9.

33. -Arnold JB, Causby R, Dip Pod G, Jones S. The impact of increasing body mass on peak and mean plantar pressure in asymptomatic adult subjects during walking. Diabetic foot ankle. 2010;1(1):5518.

34. -Riddiford-Harland DL, Steele JR, Storlien LH. Does obesity influence foot structure in prepubescent children? Int J Obes Relat Metab Disord. 2000 May;24(5):541-4.

35. -Song J, Kane R, Tango DN, Vander Veur SS, Furmato J, Komaroff E, et al. Effects of weight loss on foot structure and function in obese adults: a pilot randomized controlled trial. Gait Posture. 2015;41(1):86-92.

\section{Figures}



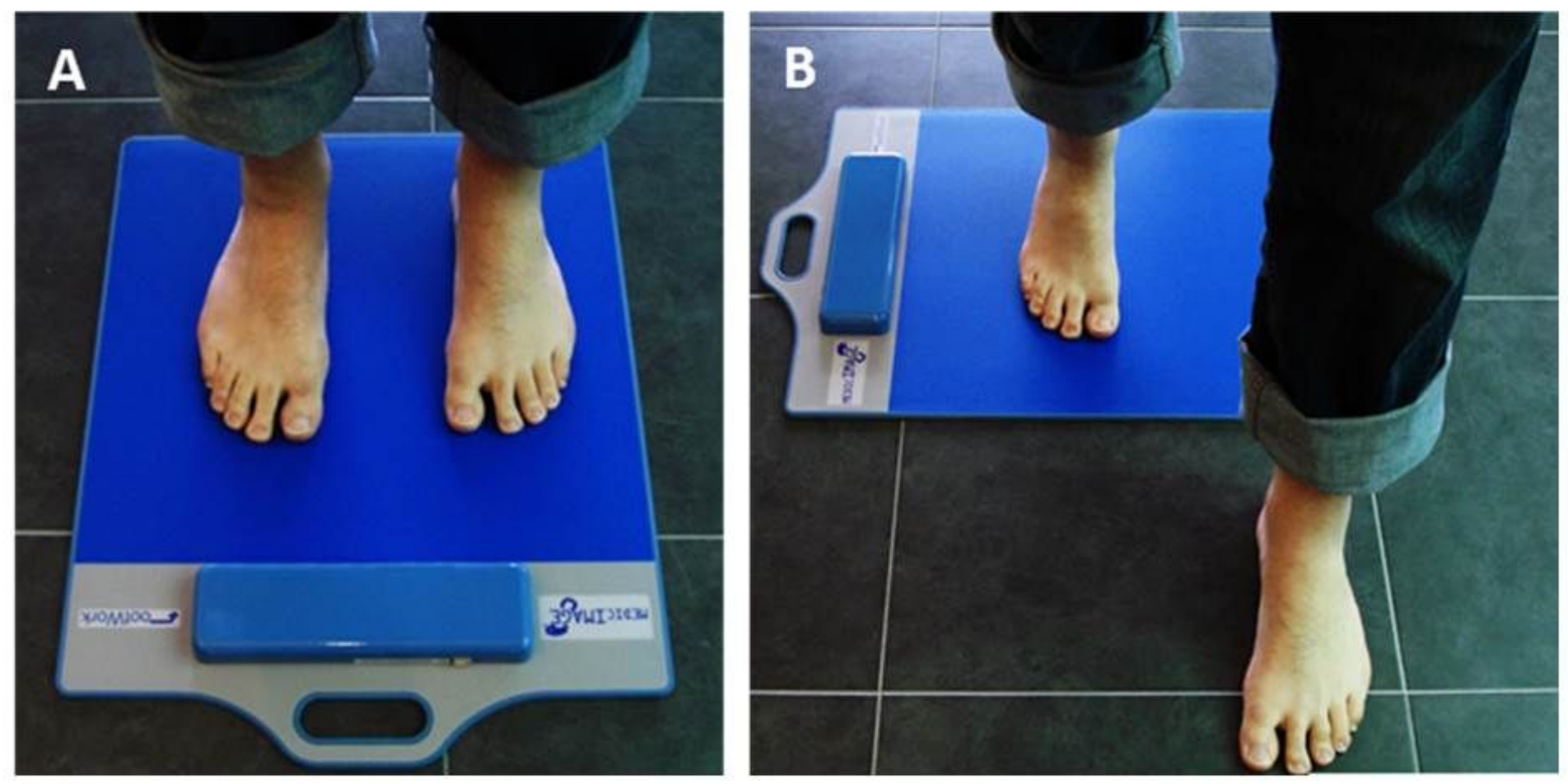

Figure 1

A static measurement, B dynamic measurement, on Footwork platform. 


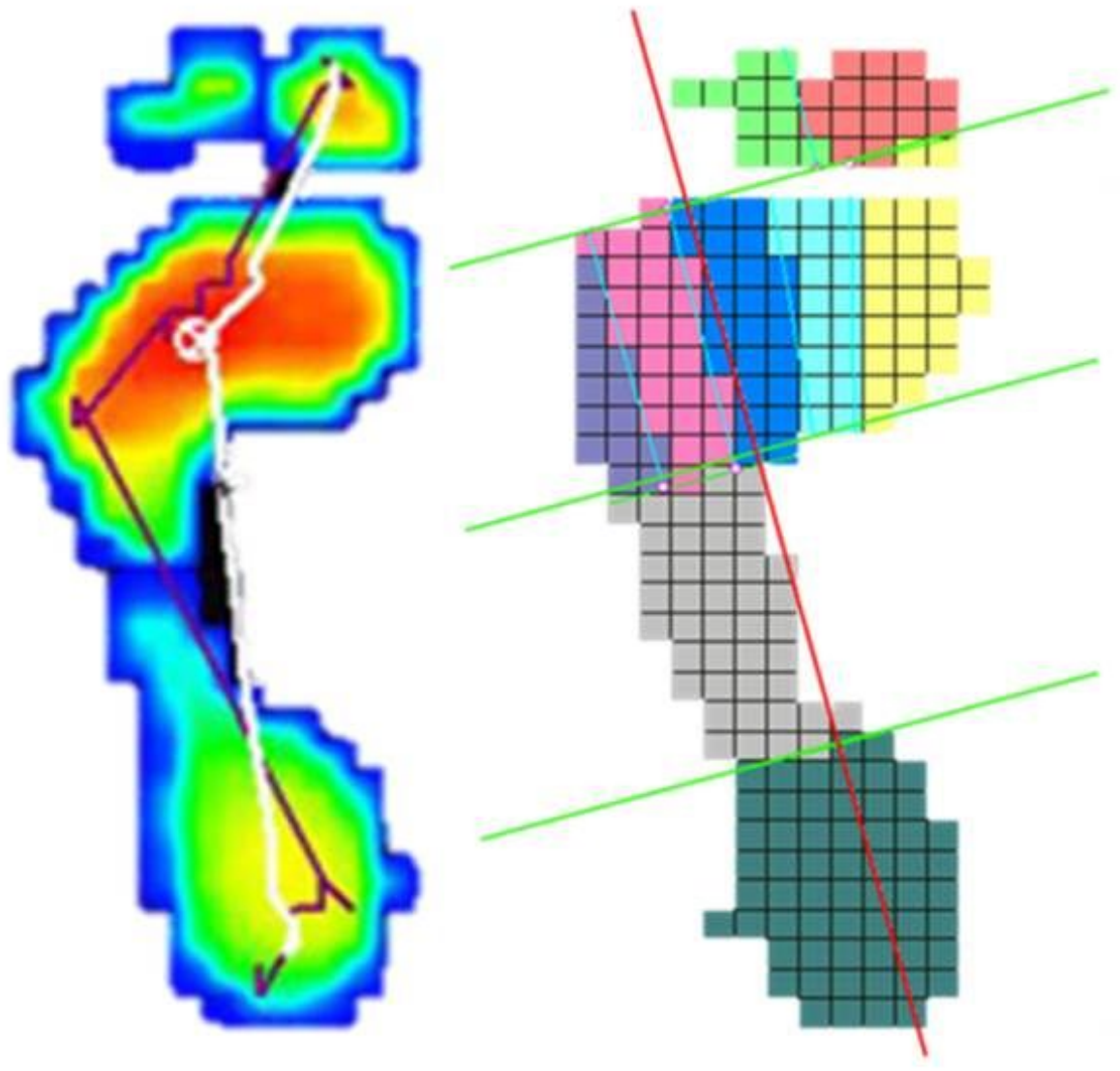

Hallux
$2-5$ toes
$1 \mathrm{MTH}$
$2 \mathrm{MTH}$
$\mathbf{3 M T H}$
$4 \mathrm{MTH}$
$5 \mathrm{MTH}$
Midfoot
Heel

Figure 2

Dynamic baropodometry footprint (left), 9 study foot areas (right). 